\title{
Influence of matrix characteristics on fracture toughness of high volume fraction $\mathrm{Al}_{2} \mathrm{O}_{3}$ / $\mathrm{Al}$-AIN composites
}

\author{
N. Nagendra and V. Jayaram \\ Department of Metallurgy, Indian Institute of Science \\ Bangalore 560 012, India
}

\begin{abstract}
The role of matrix microstructure on the fracture of Al-alloy composites with $60 \%$ volume of alumina particulates has been studied. The matrix composition and microstructure were systematically varied by changing the infiltration temperature and heat treatment. Characterisation was carried out by a combination of metallography, hardness measurements and fracture studies conducted on compact tension (CT) specimens to study the fracture toughness and crack growth in the composites. The composites show a rise in crack resistance with crack extension $(R$-curves $)$ due to bridges of intact matrix ligament formed in the crack wake. The steady state or plateau toughness reached upon stable crack growth was observed to be more sensitive to the process temperature rather than to the heat-treatment. Fracture in the composites was predominantly by particle fracture, extensive deformation and void nucleation in the matrix. Void nucleation occurred in the matrix in the as - solutionised (AS) and peak - aged (PA) conditions and preferentially near the interface in the under - aged (UA) and over - aged (UA) conditions. Micromechanical models based on cracking bridging by intact ductile ligaments were modified by a plastic constraint factor from estimates of the plastic zone formed under indentations and are shown to be adequate in predicting the steady state toughness of the composite.
\end{abstract}

\section{INTRODUCTION}


The previous companion paper presented the results of the investigation on the fracture behaviour of high volume fraction $\mathrm{Al}_{2} \mathrm{O}_{3} / \mathrm{Al}$ composites processed by pressureless infiltration. The study examined the role of reinforcement size and volume fraction on the fracture toughness and rise in crack resistance with crack growth. It was shown that although the crack growth behaviour was similar in all the composites studied, the rise in crack resistance varied with the microstructural scale and was controlled by the deformation characteristics of the matrix. The matrix deformation characteristics are however expected to be altered by changes in composition, heat treatment and interfacial characteristics. Recent studies on fracture behaviour on Al-based metal matrix composites have suggested that improvement in properties such as strength and ductility can be achieved by suitable heat-treatment [1-4]. Although significant changes in micromechanisms of fracture accompanied changes in matrix microstructure, the uniaxial tensile ductility was seen to be relatively unaffected at equivalent strength of the composites [5,6]. Studies on the fracture toughness of the composites were inconclusive and indicated that changes in matrix conditions were either beneficial [7] or had no effect at all [8,9]. With few exceptions, the fracture toughness of the composites in plane strain conditions showed little dependence on processing, materials and matrix microstructure [10]. Examination of the fracture mechanisms showed that the failure modes depended on a combination of particulate fracture, failure at or near the particulate-matrix interface, or failure initiation in the matrix [11]. In general, fracture was found to be dependent on the reinforcement characteristics (e.g. size and size distribution) as well as on the matrix properties. However, it was also shown that the percentage of particle cracking could be reduced by the formation of precipitates at or near the interface between particle and Al-alloy composites [12].

The present work focuses on the role of matrix microstructure on the fracture behaviour of Al- alloy matrices reinforced with $60 \%$ of alumina particulates. It has been sought to use the control over the interfacial microstructure and thus, in fracture mechanisms, to achieve higher toughness in the composite. Also further modification of the matrix by the formation of a refractory 
ceramic phase (AIN) present either as a dispersed [13] or an interpenetrating phase within the ductile matrix [14] raise the possibility of designing composites with lower thermal expansivity, higher thermal conductivity and greater high temperature strength. Thus, for the present study, the matrix characteristics have been altered by suitable heat-treatment (in composites with minimal content of $\mathrm{AlN}$ ) or by increased formation of AlN. The observed matrix deformation and fracture mechanisms have been analysed to elucidate the crack resistance curves of the composites. The observed fracture behaviour has been correlated with the micro-mechanical model described in the previous paper.

\section{EXPERIMENTAL PROCEDURE}

$\mathrm{Al}_{2} \mathrm{O}_{3} /(\mathrm{Al}-\mathrm{AlN})$ composites were fabricated to near-net shape by pressureless infiltration of Al-Mg-Si alloys (Al-5.5Mg-6.6Si-0.35Fe) into alumina preforms at $900-1000^{\circ} \mathrm{C}$ in $\mathrm{N}_{2}$ atmosphere [15]. The preforms were made by cold pressing and sintering of alumina powder (average particle size $23 \mu \mathrm{m}$ ) to correspond to a nominal volume fraction of $60 \%$ in the composite. The actual volume fraction was measured by an image analyser attached to an OLYMPUS microscope and the microstructure characterized for matrix hardness (SHIMADZU HMV - 2000) conditions at loads of $5 \mathrm{gmf}$ and a hold of 5 secs. To study the response of the matrix to ageing treatment, the hardness of the composites processed at $900^{\circ} \mathrm{C}$ was measured after artificial aging at $145,170,195$ and $220^{\circ} \mathrm{C}$ for periods of 5-3000 mins. The fabricated composites were later sectioned into compact tension (CT) specimens for fracture studies. Studies were done according to ASTM E399, as discussed in the previous paper, and the fractured surface examined under a scanning electron microscope ( SEM - JEOL 840 SM). 


\section{RESULTS}

\section{Microstructures}

The microstructures of the composite processed are shown in figure 1 (a-d) and the microstructural parameters are given in table 1 . Composites processed at $900^{\circ} \mathrm{C}$ in the assolutionised condition (Fig. 1 a) show uniformly distributed alumina particles in a matrix having a distribution of $\mathrm{Mg}_{2} \mathrm{Si}$ and free Si. Artificial aging at temperatures of $145-220^{\circ} \mathrm{C}$ resulted in changes in the matrix hardness (Fig 2). At any aging temperature, a slight drop in the matrix hardness was initially observed at short aging time; further ageing increased the matrix hardness significantly till a peak value was reached; while longer aging times resulted in a drop in hardness values. The time for peak matrix hardness varied with the aging temperature. Shorter aging times were required to reach peak hardness at higher temperature. The microstructural observations indicated that $\mathrm{Mg}_{2} \mathrm{Si}$ in the matrix had started to coarsen and that the coarsening increased with aging temperature and time. The maximum hardness reached was $165 \mathrm{VHN}$ and the matrix showed presence of large precipitates of $\mathrm{Mg}_{2} \mathrm{Si}$. At $220^{\circ} \mathrm{C}$ and 12 hours (Over Aged condition), the precipitates were found as very coarse aggregates in the matrix (Fig $1 \mathrm{~b}$ ) and the matrix hardness again dropped.

The peak hardness of the matrix was also observed to be dependent on the aging temperature and times. At $220^{\circ} \mathrm{C}$, the peak hardness was reached at 5 mins. as compared to 1200 mins. at $145^{\circ} \mathrm{C}$. However, a critical temperature of $195^{\circ} \mathrm{C}$ and ageing time of 180 mins. was observed for the matrix to reach the highest hardness in all the conditions studied. At temperatures on either side of the critical temperature, the matrix hardness was lower at all ageing times. The matrix of the composite aged at lower temperature of $145^{\circ} \mathrm{C}$ shows precipitates that further coarsened upon ageing at higher temperatures. The precipitates could not be resolved optically, but SEM studies indicated a distinct change in morphology upon ageing under different conditions. At 
$145^{\circ} \mathrm{C}$ and 1 hour (UA), the precipitates showed a fine needle-like structure of $\sim 0.25 \mu \mathrm{m}$ thickness and $\sim 3 \mu \mathrm{m}$ in length and at $220^{\circ} \mathrm{C}, 12$ hours (OA) the precipitates were large $(\sim 4-6 \mu \mathrm{m})$ and irregular in shape. EDS analysis revealed the precipitates to be rich in $\mathrm{Mg}$ and $\mathrm{Si}$ indicating them to be $\mathrm{Mg}_{2} \mathrm{Si}$ precipitates. Composites processed at higher temperatures showed increased formation of AlN (Fig $1 \mathrm{c} \& d$ ) and the matrix hardness increased steeply by up to 2.5 times over the values seen in composites processed at $900^{\circ} \mathrm{C}$

\section{Fracture toughness and R-curves}

The fracture toughness of the composites showed a strong dependence on the processing temperature of the composites. A drop in the fracture toughness was observed from $10.7 \mathrm{MPa} \sqrt{\mathrm{m}}$ in composites processed at $900^{\circ} \mathrm{C}$ to $7.2 \mathrm{MPa} \sqrt{\mathrm{m}}$ in composites processed at $1000^{\circ} \mathrm{C}$. However, the matrix ageing conditions did not significantly affect the fracture toughness. Toughness increased from 10.7 to $11.4 \mathrm{MPa} \sqrt{\mathrm{m}}$ in the UA condition while, a drop to $9.5 \mathrm{MPa} \sqrt{\mathrm{m}}$ was observed in the PA condition. Upon overaging, the composite regained its toughness to $\sim 10.1 \mathrm{MPa} \sqrt{\mathrm{m}}$.

In composites processed at $900^{\circ} \mathrm{C}$, the crack resistance curves (Fig 3 a) indicated that the curves started from an initial value of $5 \mathrm{MPa} \sqrt{\mathrm{m}}$ in the as-solutionised and PA conditions, as compared to 3-4 MPa $\sqrt{\mathrm{m}}$. in the UA and OA conditions. The plateau toughness of $\sim 14-16 \mathrm{MPa} \sqrt{\mathrm{m}}$ was not significantly changed upon ageing treatment, but it was observed that composites in UA conditions accommodated larger crack growth prior to fracture. On the other hand, PA and OA composites displayed lower toughness while composites in OA condition also needed more crack growth to reach equivalent toughness values. The crack resistance curves of composites processed at different temperature (Fig. $3 \mathrm{~b}$ ) showed that while a plateau toughness of $16 \mathrm{MPa} \sqrt{\mathrm{m}}$ was observed in composites processed at $900^{\circ} \mathrm{C}$, the corresponding values dropped to $9.3 \mathrm{MPa} \sqrt{\mathrm{m}}$ and 6.8 $\mathrm{MPa} \sqrt{\mathrm{m}}$ in composites processed at 950 and $1000^{\circ} \mathrm{C}$ respectively. The plateau toughness regime was well formed and extended over significant crack growth in composites processed at $1000^{\circ} \mathrm{C}$. 


\section{Fractography}

The macro and micro features of fracture were similar in all the composites tested. Composites processed at $900^{\circ} \mathrm{C}$ (AS) exhibited a high degree of particle cracking and extensive deformation of the matrix (Fig. 4 a). The matrix did not exhibit the ductile fracture that is typical of metals but deformed as well formed ridges with the nucleation of voids predominantly at the centre of the matrix (Fig. 4 b). In the UA condition, a decrease in particle cracking and an increase in void formation near the interface were observed (Fig $4 \mathrm{c}$ ). The fracture also revealed the presence of fine needle-like precipitates (Fig. 5 a) in the matrix close to the particle. The precipitates appeared to have participated in the fracture processes by aiding void nucleation near the particle/matrix interface. In the PA condition, large precipitates were found in the matrix and were observed to be involved in the fracture process of the matrix by void nucleation. However, void nucleation was further away from the matrix/particle interface and the matrix as a whole deformed as ridges that were shallower than those seen in the underaged samples. In the OA condition, reduced particle cracking and enhanced void nucleation at the particle/matrix interface characterised failure (Fig. 4 d). However, the overall fracture characteristics remained unchanged and the matrix deformed as ridges with much higher stretch as compared to in the peak aged condition. The large precipitates (Fig. 5 b) observed in the matrix appeared to have had a role in the fracture of the matrix by aiding preferential void nucleation. With increased formation of AlN in the matrix, secondary fine dimples corresponding to the AIN particle size were observed in the matrix close to the particles $\left(\right.$ at $950^{\circ} \mathrm{C}$ ), while the rest of the matrix failed by a ridge like manner (Fig. 6 a). In composites processed at $1000^{\circ} \mathrm{C}$, matrix deformation was reduced to pockets between the $\mathrm{AlN}$ particle grown into the matrix from near the alumina/matrix interface. The matrix had deformed as a ridge with a shallow plastic stretch (Fig. 6 b) and void nucleation was observed at the centre of the matrix ligament. 


\section{Discussion}

Infiltration by molten Al-alloys into porous alumina preform enables fabrication of composites with high volume fraction of alumina particulates dispersed in the matrix. The presence of ceramic particulates is known to modify the matrix characteristics by inducing changes in composition resulting from interfacial reactions between the matrix and the reinforcement $[16,17]$. The microhardness of the matrix processed at $900^{\circ} \mathrm{C}$, was nearly twice that of the matrix alloy and can be attributed to precipitation of intermetallic $\mathrm{Mg}_{2} \mathrm{Si}$, free $\mathrm{Si}$ along with some fine precipitates of AlN in the matrix. The loss of $\mathrm{Mg}$ during processing enriches the $\mathrm{Si} / \mathrm{Mg}$ ratio resulting in increased precipitation of $\mathrm{Mg}_{2} \mathrm{Si}$. With increased processing temperature, the enhanced formation of AlN in the matrix results in increased matrix hardness [15].

The presence of ceramic particulate influences the ageing kinetics of the matrix and precipitation kinetics is accelerated when compared to that of the un-reinforced alloy [18-22]. The large difference in thermal expansion coefficient between the matrix $\left(\alpha_{\mathrm{al} \text {-alloy }} \sim 25 \times 10^{-6}{ }^{\circ} \mathrm{C}^{-1}\right)$ and reinforcement $\left(\alpha_{\text {alumina }} \sim 8 \times 10^{-6}{ }^{\circ} \mathrm{C}^{-1}\right)$ is expected to introduces residual stresses and dislocations when any thermal treatment is applied to these materials $[19,20]$. This factor, combined with the fact that precipitation is largely a diffusion aided process, tends to increase the rate of precipitation in the matrix. The precipitation kinetics in particular is observed to be strongly dependent on the ageing temperature [23].

Studies on Al-Mg-Si alloys [24] and cast $6061 \mathrm{Al}-10 \% \mathrm{Al}_{2} \mathrm{O}_{3}$ composites [25] have indicated that the precipitation sequence of brittle $\mathrm{Mg}_{2} \mathrm{Si}$ depends on the ageing temperature: below a critical temperature, the precipitation sequence is observed to be Si-vacancy clusters $\rightarrow$ GuinierPreston zones $\rightarrow$ partially coherent $\beta^{\prime \prime} \rightarrow$ semi-coherent $\beta^{\prime} \rightarrow \beta$ (sequence 1 ); and above the critical temperature, nucleation is heterogeneous and $\beta^{\prime}$ nucleates directly on dislocations. However, the 
final precipitation sequence was accepted to be $\beta^{\prime \prime} \rightarrow \beta^{\prime}$ irrespective of the ageing temperature employed [26-29]. The critical temperature between the two domains defined by this transition behaviour can be explained from the changes in the precipitation sequence $[28,30]$. At $145^{\circ} \mathrm{C}$, a fine and uniform precipitation consisting of $\beta^{\prime}$ needles has been reported in the matrix; and the needle radius is not observed to change significantly with ageing time as compared to changes in its length [26]. The observed precipitate morphology of $\beta^{\prime}$ in this case is indicative of the first precipitation sequence being active. At $220^{\circ} \mathrm{C}, \beta^{\prime}$ precipitates are known to nucleate heterogeneously within the matrix, implying the occurrence of sequence 2 . Thus, based on the hardening kinetics of the matrix at temperatures of $145-220^{\circ} \mathrm{C}$, it is possible to fix conditions corresponding to the optimally under aged (UA), peak aged (PA) and over aged (OA) matrix hardness and strength in the composite.

\section{Toughness and R-curves}

The $R$-curves for the composites computed from the load vs. COD data were observed to start from $\sim 4-5 \mathrm{MPa} \sqrt{\mathrm{m}}$ which can be ascribed to be the intrinsic toughness of the microstructure, and reached a plateau toughness values of 6-16 $\mathrm{MPa} \sqrt{\mathrm{m}}$ after stable crack growth. The rise in fracture resistance upon crack extension can be attributed to the crack growth characteristics in the composites as described in the previous paper. When interfacial failure or particle cracking precedes the ductile fracture of the metal as seen in many $\mathrm{P} / \mathrm{M}$ composites $[31,32]$, the deformation of the matrix is very limited before the initiation of fracture at the particle. The intact undeformed matrix ligaments thus formed behind the crack tip act as bridges between the opposing faces of the crack, preventing excessive crack opening and thereby, reducing the crack driving force or the stress intensity factor $K_{I}$ at the crack tip. 
The effect of ageing on the fracture response of the composites largely depends on the growth of interface cracks. The crack is known to take paths along the interface in the metal or ceramic depending on the local loading conditions such as phase angle and properties of the constituents $[33,34]$. For $\mathrm{Al}_{2} \mathrm{O}_{3} / \mathrm{Al}$ system, it has been shown that the crack stays in $\mathrm{Al}$, but dives into the ceramic if the yield strength of the metal is raised by additions of $\mathrm{Mg}$ [35]. However, the presence of a soft Al layer next to the interface can deflect the interface crack back into the Al layer upon which it gets arrested by the extensive plasticity of the ductile metal layer as observed in $\mathrm{Al}_{2} \mathrm{O}_{3} / \mathrm{Al}-\mathrm{Cu}$ composites [36]. In the present case, the ageing conditions imposed on the matrix of the composites leads to marked changes in the precipitation sites and morphology of $\mathrm{Mg}_{2} \mathrm{Si}$ precipitates. At UA conditions, the precipitates are formed near the interface possibly leading to local depletion of $\mathrm{Mg}$ in the matrix. The depletion of $\mathrm{Mg}$ reduces the strength of the Al-layer near the matrix resulting in extensive plasticity and failure by large-scale void formation. In the peakaged condition the precipitates are relatively finer and are formed in the matrix away from the interface. However, upon over ageing the precipitates further coarsen resulting in loss of $\mathrm{Mg}$ in the matrix near the interface, thus locally reducing the matrix strength. The above argument gains further credence due to the seemingly lower starting toughness $K_{o}$ in the $K_{R}$ curves and smaller incidence of particle cracking observed in UA and OA conditions as compared to in AS and PA conditions. Since $K_{o}$ is an intrinsic material property and is assumed to be strongly dependent on the $\mathrm{Al}_{2} \mathrm{O}_{3} / \mathrm{Al}$ alloy interface, the loss of $\mathrm{Mg}$ near the interface can lead to considerable weakening, resulting in a reduced $K_{o}$. Increased formation of AlN, however, does not influence the failure mechanism in the composites. In composites processed at $950^{\circ} \mathrm{C}$, shallow dimples present on the deformed ridge or near the interface indicated the presence of fine AlN in the matrix. Increased AlN in the matrix (at $1000^{\circ} \mathrm{C}$ ) resulted in near isolation of the Al-alloy from the reinforcing alumina particle and the alloy had seemingly deformed under constraint from AlN particles. 
Although, the presence of precipitates results in local changes in failure mechanisms, the matrix continues to deform as ridges due to the constraints applied by the elastic particle. A relative study on the constraints imposed by the largely elastic particles can be made by dynamic indentation and measuring the induced displacement [15]. The plastic zone thus formed was calculated $[37,38]$ from the load-displacement curves of the matrix

$$
\left(\frac{c}{h}\right)^{3}=3.639\left[\frac{(E / Y) \tan \beta+4(1-2 v)}{(1-v)}\right]
$$

where " $c$ " is the plastic zone radius, $\mathrm{h}$ is the depth of plastic penetration, $E, Y$ and $v$ are the elastic modulus, yield strength and Poisson's ratio, respectively, of the indented material, and $\beta$ is the cone angle of an equivalent conical indentor. Assuming the properties of the base alloy as $E=69$ GPa, $Y=276 \mathrm{MPa}\left(6061-\mathrm{Al}-\mathrm{Mg}-\mathrm{Si}\right.$ alloys), $v=0.33$ and $\beta=19.69^{\circ}$ for the indentor in use, the measured plastic penetration enables an estimate of the plastic zone radius from equation (1). The ratio of the plastic zone formed in the base alloy to that in the composite matrix can be assumed to give a measure of the constrained deformation of the matrix due to the presence of elastic particles and is tabulated in table 1.

The measured and the calculated steady state toughness of the composites are given in table 2 and showed a good correlation in composites processed at $900^{\circ} \mathrm{C}$. Estimates, from fracture studies, of the energy dissipated upon deformation indicated a relationship with void nucleation in the matrix. Void nucleation at the interface as observed in UA and OA conditions resulted in release of constraints allowing increased plastic stretch in the matrix ligament. On the other hand, the presence of precipitates in the matrix (AS and PA conditions) led to inherent loss of ductility in the matrix manifesting in shallow plastic stretch to failure. However, although significant changes in sites for void nucleation are observed their overall contributions to the energy dissipated during deformation were seemingly minimal as indicated by both the measured and calculated toughness. In composites processed at 950 and $1000^{\circ} \mathrm{C}$, the predicted toughnesses were an overestimate and 
was probably due to the large value of $\sigma_{y}$ assumed for the matrix in calculating $K_{s s}$. The values of $\sigma_{y}$ as determined from the load-displacement curves of the matrix has significant contributions from the stiff AlN phase which however do not contribute to the toughening process in the crack wake. Recalculating the values of $\sigma_{y}$ of the matrix only (assumed to be constrained by AlN) from hardness measurements in coarse particle composites processed at similar temperatures [15] indicated that the matrix had $\sigma_{y}$ values of $380 \mathrm{MPa}\left(\right.$ at $950^{\circ} \mathrm{C}$ ) and $419 \mathrm{MPa}\left(\right.$ at $1000^{\circ} \mathrm{C}$ ) respectively. Using the recalculated values of $\sigma_{y}$, gives toughness values of 11.5 and $10.4 \mathrm{MPa} \sqrt{\mathrm{m}}$, respectively, which lie much closer to the measured values.

The micromechanical analyses of crack tip profiles are shown in Fig. 7 a-b. As seen, the measured critical COD $2 \mathrm{u}^{*}$, in composites processed at $900^{\circ} \mathrm{C}$ (Fig. 7 a) lie far away from the theoretical computed profiles indicating that the measured steady state toughness values may not be a crack independent property of the composite. However, in composites processed at 950 and $1000^{\circ} \mathrm{C}$, the critical COD $2 \mathrm{u}^{*}$ were much smaller and lie closer to the theoretical crack profiles. Thus, measured steady state toughnesses in these composites are presumably very close to their independently measured fracture toughnesses. Computations of the bridging zone (table 2) also lend support to the argument by indicating that this zone forms a large component of the overall crack length in composites processed at $900^{\circ} \mathrm{C}$ as compared to composites processed at 950 and $1000^{\circ} \mathrm{C}$.

The role of matrix characteristics on the $R$-curve behaviour of the composites can thus be summarised as :

\section{Influence of thermal ageing}

Composite subjected to thermal ageing treatment showed only slight differences in their fracture toughness and peak toughness. The precipitates formed in the matrix participate in the fracture behaviour and are expected to reduce the strain to failure of the matrix. The contribution to the changes in the toughness increment is thus due to the prevailing fracture mechanism in the 
ductile matrix bridges. Enhanced void nucleation at the particle/matrix interface as opposed to void nucleation in the matrix reduces the energy consumed in the fracture processes of the bridging matrix ligaments as suggested by the larger crack extension to failure in the underaged and overaged samples. However, the changes in toughness upon ageing are marginal and consistent with similar observations in aluminium matrix composites with $10-20 \%$ particulate fraction $[8,9]$.

\section{Influence of process temperature}

Composite processed at higher process temperature indicated formation of AlN ceramic in the matrix and corresponding drops were observed in both the fracture toughness and plateau toughness. In addition, composites processed at 950 and $1000^{\circ} \mathrm{C}$ showed a steeper $R$-curve with a better defined steady-state toughening zone occurring at lower a/W. The steeper rise in crack resistance is due to the increased constraint $(\mathrm{P} \sim 2)$ on the deforming matrix. The formation of a larger steady state toughening zone is probably due to the smaller bridging zones that exist behind the crack tip.

\section{CONCLUSIONS}

The fracture behaviour of $\mathrm{Al}_{2} \mathrm{O}_{3} /(\mathrm{Al}-\mathrm{AlN})$ processed by pressureless infiltration of Al-alloys have been studied. The investigation has shown the importance of processing conditions or ageing treatment on the micromechanisms of fracture and macroscopic fracture toughness of the composites. Based on our observation and analysis, the following conclusions have been reached:

1. The measured toughness of the composites ranged from 7-11 MPa $\sqrt{\mathrm{m}}$ depending on the ageing and processing conditions. The fracture toughness was dependent on crack extension and a high plateau toughness of $16 \mathrm{MPa} \sqrt{\mathrm{m}}$ was measured in composites processed at $900{ }^{\circ} \mathrm{C}$ in the assolutionised condition. Ageing conditions did not significantly alter either the fracture 
toughness or the plateau toughness reached upon stable crack growth. However, with increasing process temperature and the greater formation of AlN, a decrease in fracture toughness and plateau toughness were observed.

2. Fracture in the composites was predominantly due to particle cracking and extensive deformation in the matrix. Additionally, upon ageing to different conditions significant changes in failure mechanism were observed. Although, the matrix had deformed as ridges, preferential failure by void nucleation near the particle/matrix interface was observed in UA and OA conditions. In contrast, in AS and PA conditions void nucleation was centred in the matrix.

3. Two types of $\mathrm{Mg}_{2} \mathrm{Si}$ precipitates were found in the matrix aged to different conditions. In UA conditions, the precipitates were needle like and found near the interface while upon PA and $\mathrm{OA}$, the precipitates were acicular and formed in the matrix. The preferential formation of precipitates near the interface were found to influence the failure mechanism by local reduction of matrix strength.

4. Known micromechanical models based on crack bridging by intact ductile matrix ligaments can predict the plateau toughness and the $R$-curve behaviour of the composites. The model modified by experimentally determined constraints that influence the matrix strength and plastic stretch to failure predicts the plateau toughnesses of the composite processed at $900^{\circ} \mathrm{C}$ within reasonable limits.

\section{ACKNOWLEDGEMENTS}

The authors would like to acknowledge A.H Chokshi, M.K. Surappa and B. Dutta, all of Department of Metallurgy, Indian Institute of Science for their help in the use of Instron and dynamic measurements of hardness, respectively, and C.R.L Murthy and M.R. Bhat from the department of Aerospace Engineering for their help in measurements of elastic modulus. Financial 
support for the present work was provided by the Board of Research Nuclear Sciences, Government of India 


\section{REFERENCES}

1. G.J. Mahon, J.M. Howe and A.K. Vasudevan, , Acta Metall. Mater., 38, 1503 (1990)

2. J. Llorca, A. Needleman and S. Suresh, Acta Metall. Mater. 39, 2317 (1991)

3. A.J. Shakesheff, J. Mat. Sci. 30, 2269 (1995)

4. G.A. Rozak, A.A. Altmisolgu, J.J. Lewandowski and J.F. Wallace, J. Compos. Mater., 26, 2076 (1992)

5. J.J. Lewandowski, C. Liu and W.H. Hunt: in "Processing and Properties of Powder Metallurgy Composites", edited by P. Kumar et. al., , Warrendale, PA, TMS/AMIE 17 (1988)

6. C. Liu, S. Pape and J.J. Lewandowski, in H. Ishida (ed.), Interfaces in polymer, ceramic and metal matrix composites, Elsevier Science, New York, P 513 (1988)

7. M. Manoharan and J.J. Lewandowski, Int. J. Fract. 40, R31 (1989)

8. T.G.A. Doel, M.H. Loretto and P. Bowen, Composites, 24, 270 (1993)

9. T.G.A. Doel and P. Bowen, Mat. Sci. and Tech. 12, 586 (1996)

10. B. Roebuck and J.D. Lord, Mat. Sci. and Tech. 12, 1199 (1990)

11. Y. Flom and R.J. Arsenault, Acta Metall. 37, 2413 ((1989)

12. R.O. Ritchie, Mat. Sci. Eng. 103A, 15 (1988)

13. M.K. Aghajanian, J.T. Burke, D.R. White and A.S. Nagelberg, SAMPE Quarterly, 20, 43 (1989)

14. E. Breval, M.K. Aghajanian, J.P. Biel and S. Antolin, J. Am. Ceram. Soc., 76 , 1865 (1993)

15. N. Nagendra, Ph.D thesis, Indian Institute of Science, Bangalore, 1997

16. H. Ribes amd M. Suery, Scripta Metall. 23, 705 (1989)

17. D.J. Trowle and C.M. Friend, Scripta Metall. Mater. 26, 437 (1992)

18. T.G. Nieh and R.F. Karlak, Scripta Metall. 18, 25 (1984)

19. T. Christman and S. Suresh, Acta Metall. 36, 1691 (1988) 
20. M. Vogelsang, R.J. Arsenault and R.M. Fisher, Metall. Trans. 17A, 379 (1986)

21. R.J. Arsenault and N. Shi, Mat. Sci. Eng. 81, 175 (1986)

22. T. Christman, A. Needleman and S. Suresh, Acta. Metall. 37, 3029 (1989)

23. K.K Chawla. A.H. Esmaeli, A.K. Datye and A.K. Vasudevan, Scripta Metall. Mater. 25, 1315 (1991)

24. D. DaFir, G. Guichon, R. Borelly, S. Cardinal, P.F. Gobin and P. Merle, Mat. Sci. and Eng., 144A, 311 (1991)

25. L. Salvo and M. Suéry, Mat. Sci. and Eng. 177A, 19 (1994)

26. M.H. Jacobs, Phil. Mag. 26, 1 (1972).

27. G. Thomas, J. Inst. Met. 90, 57 (1962).

28. R.C. Dorward, Metall. Trans. 4A, 507 (1973)

29. D.W. Pashley, M.H. Jacobs, J.T. Vietz, Philos. Mag. 16, 51 (1967)

30. J.M. Papazian, Metall. Trans. 19A, 2945 (1988)

31. J.K. Shang, W. Yu and R.O. Ritchie, Mat Sci. Eng 102 A, 191 (1988)

32. M. Manoharan and J.J. Lewandowski, Scripta Metall. 23, 301 (1989)

33. M. He and J.W. Hutchinson, Int. J. Solids struct. 25, 1053 (1989)

34. J.W. Hutchinson and Z. Suo, Adv. Appl. Mech. 29, 63 (1992)

35. A.G. Evans, B.J. Dalgleish, M. He and J.W. Hutchinson, Acta Metall. 37, 3249 (1989)

36. G. Liu, Z. Zhang and J.K. Shang, Acta.Metall. Mater. 42, 271 (1994)

37. K.L. Johnson, J. Mech. Phys. Solids 18, 115 (1970)

38. J.W. Leggoe, X.Z. Hu, M.V. Swain and M.B. Bush, Scripta. Metall. Mater. 31, 577 (1994) 


\section{FIGURES}

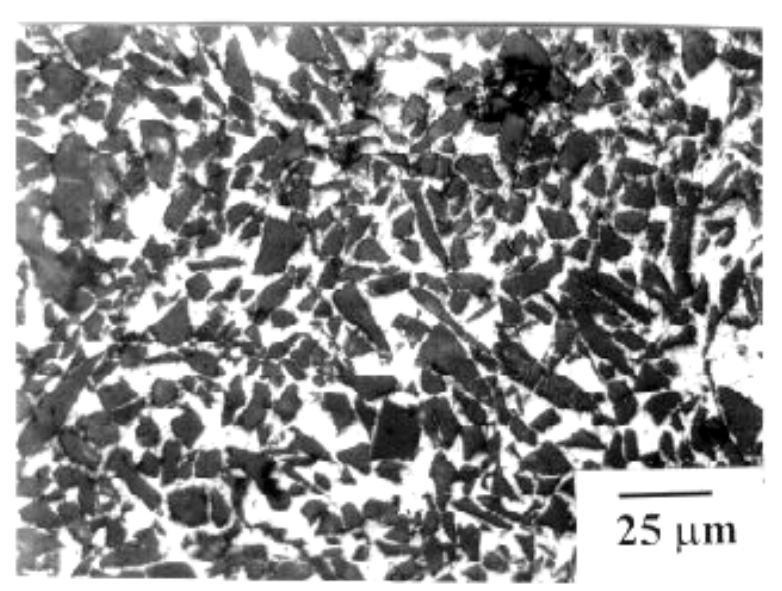

a)

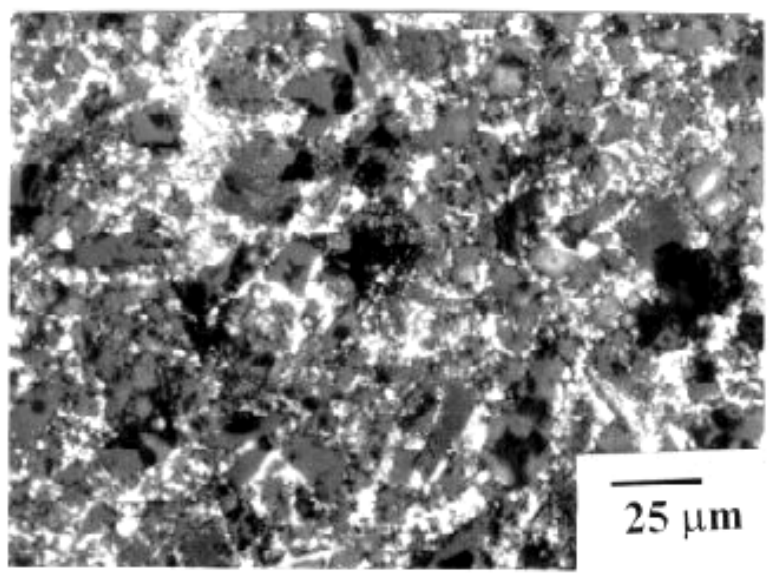

c)

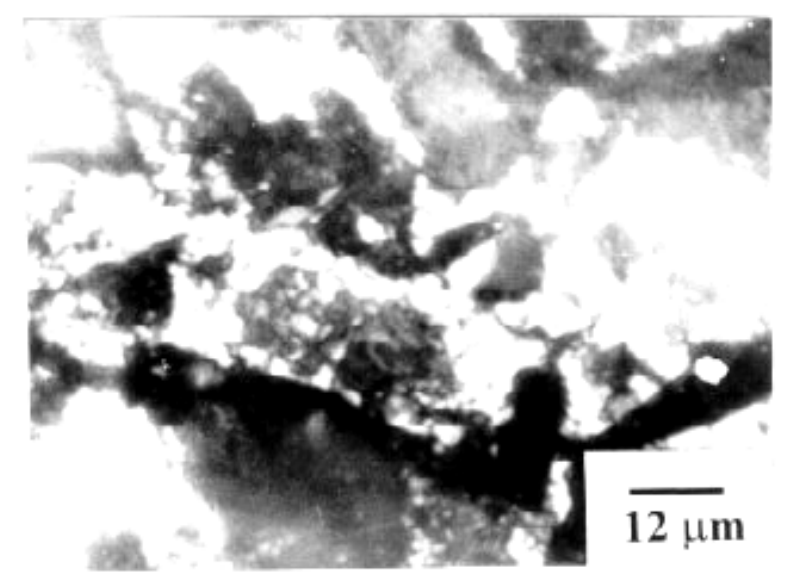

b)

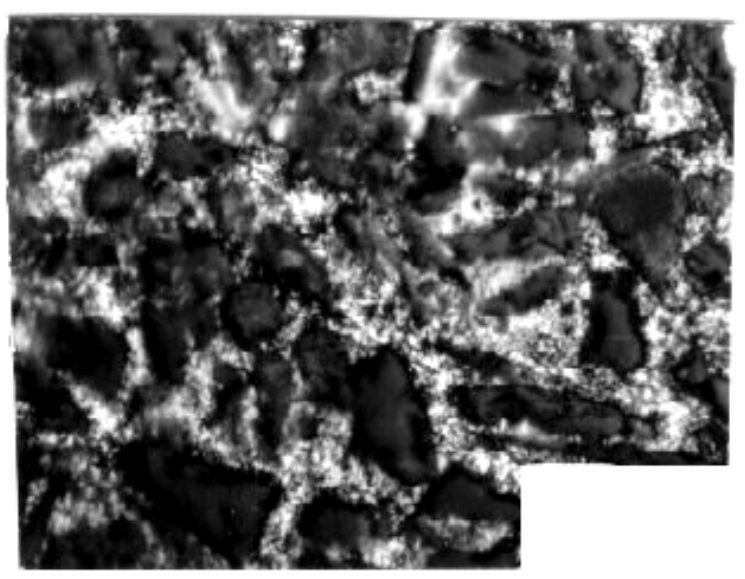

d)

Fig. 1 Microstructure of the composites a) processed at $900^{\circ} \mathrm{C}$; b) precipitate morphology in $\mathrm{OA}$ condition; c) processed at $950^{\circ} \mathrm{C}$ and d) processed at $1000^{\circ} \mathrm{C}$ 


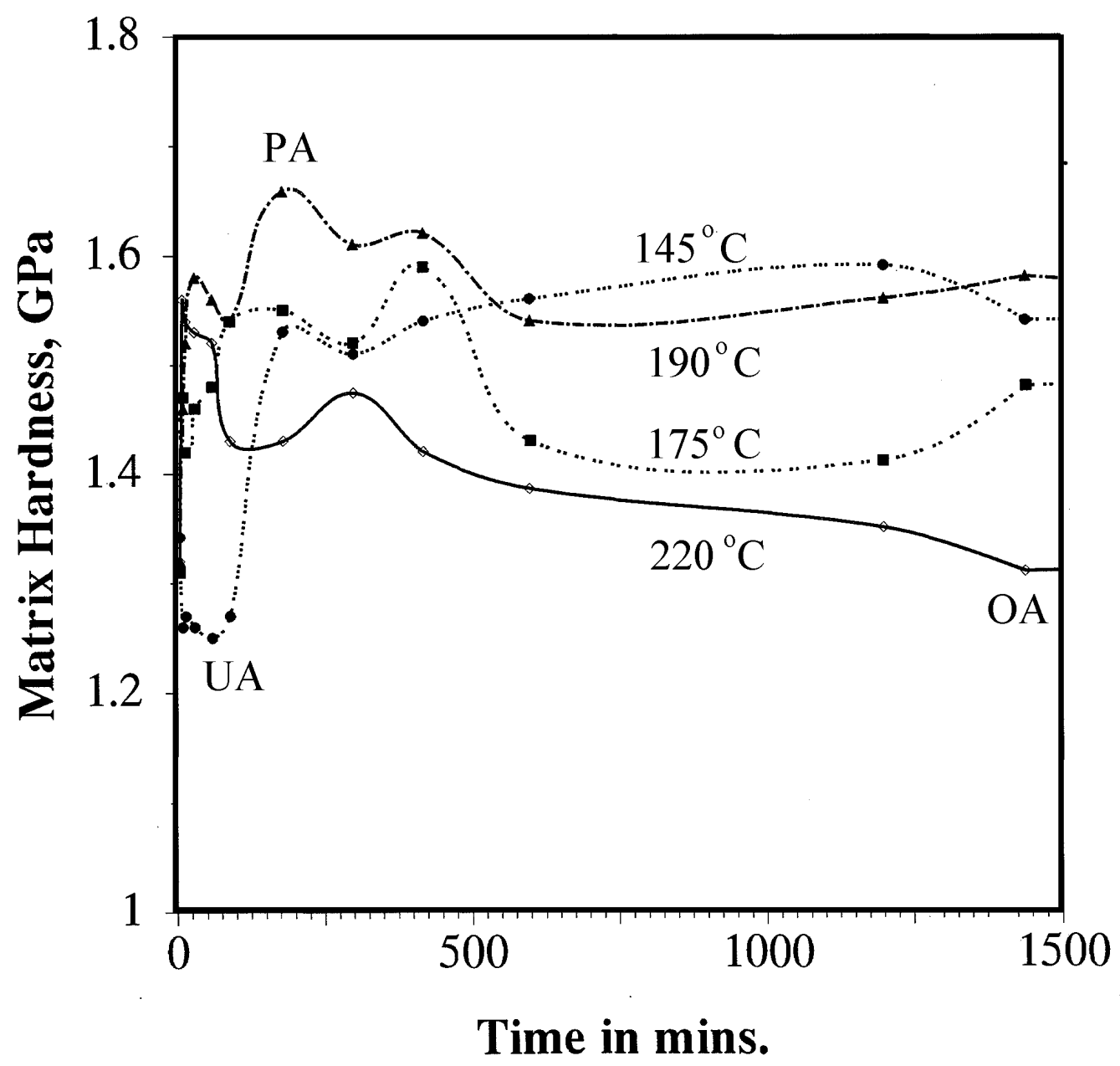

Fig. 2 Matrix hardness as a function of ageing temperature and time 


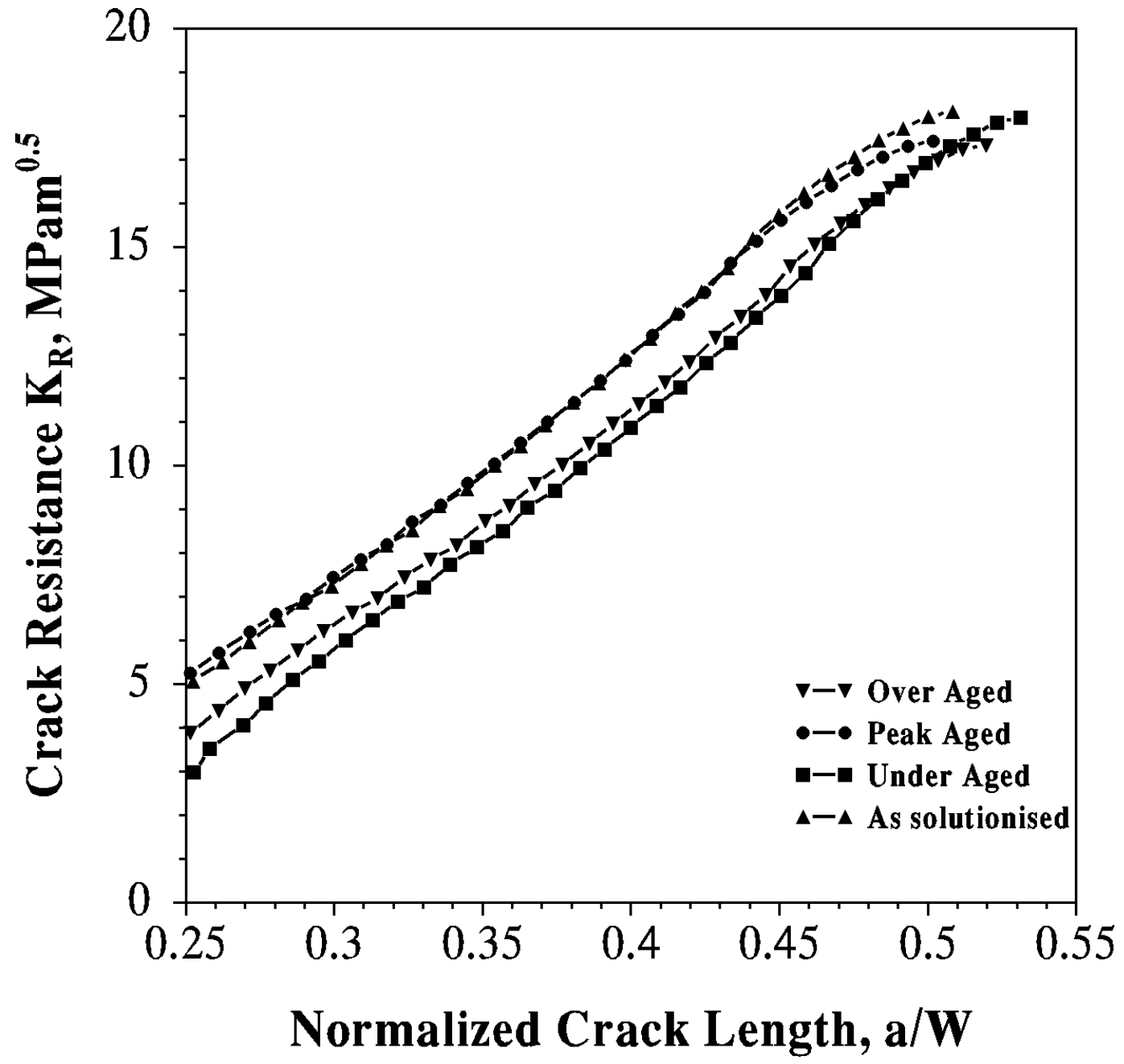

Fig. 3 a 


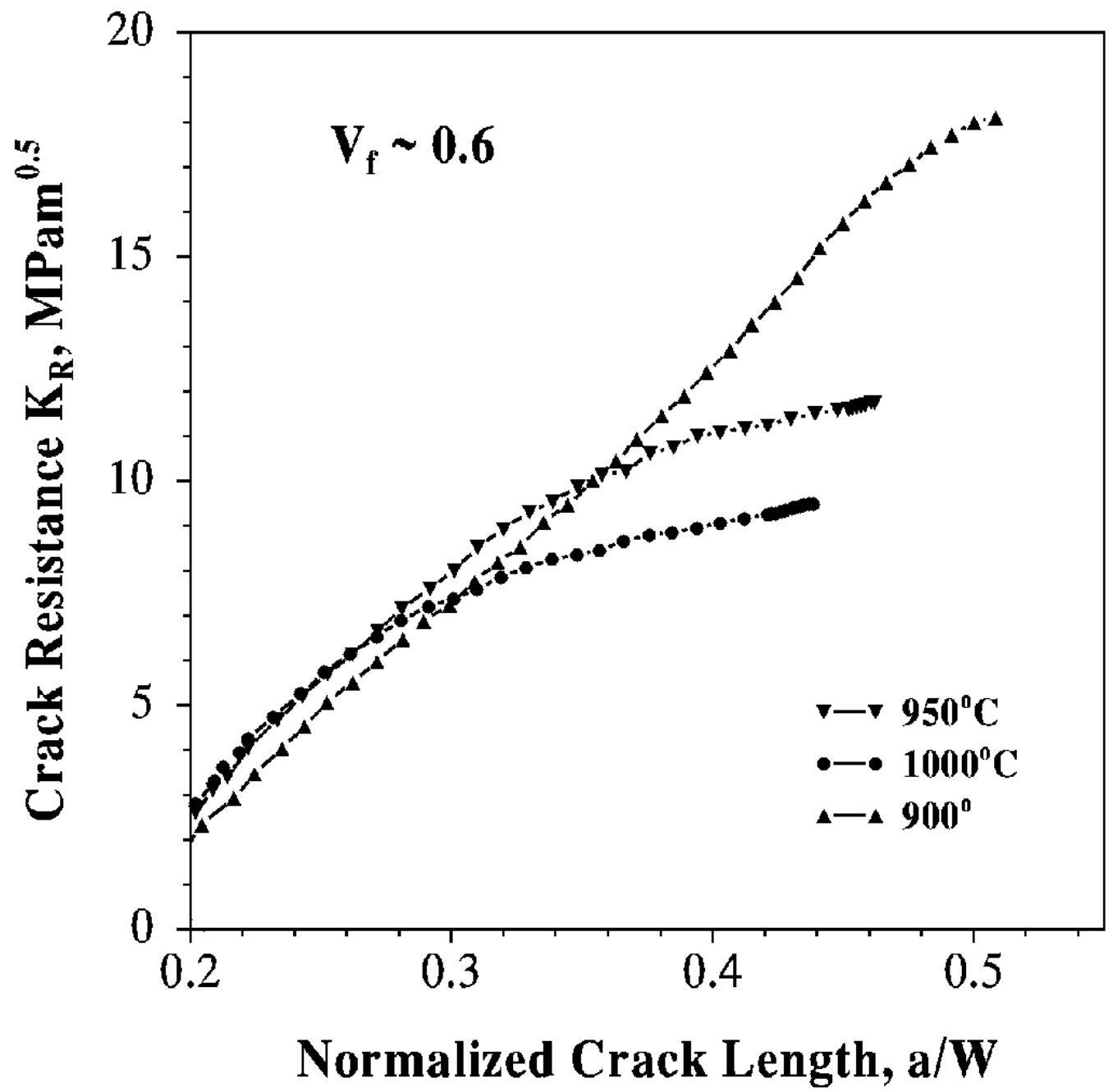

Fig 3 b

Fig. 3 Rise in crack resistance with crack extension in the composites with variation : a) ageing condition and b) process conditions. 


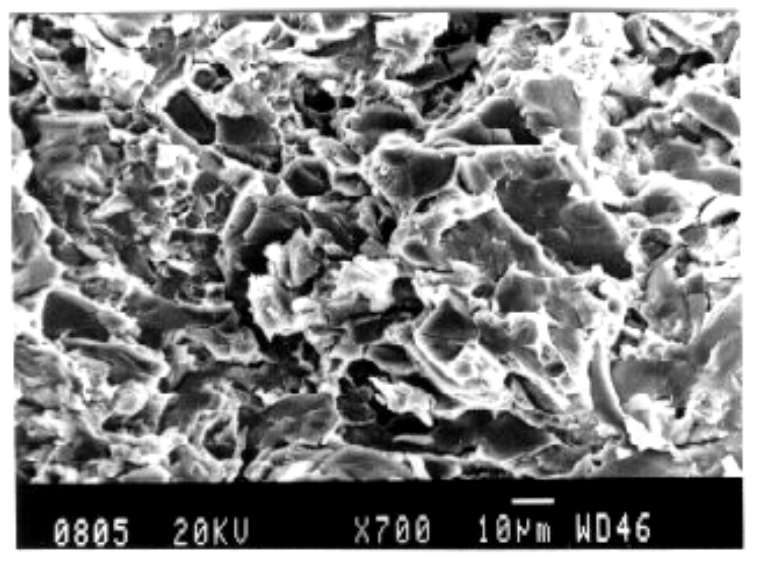

(a)

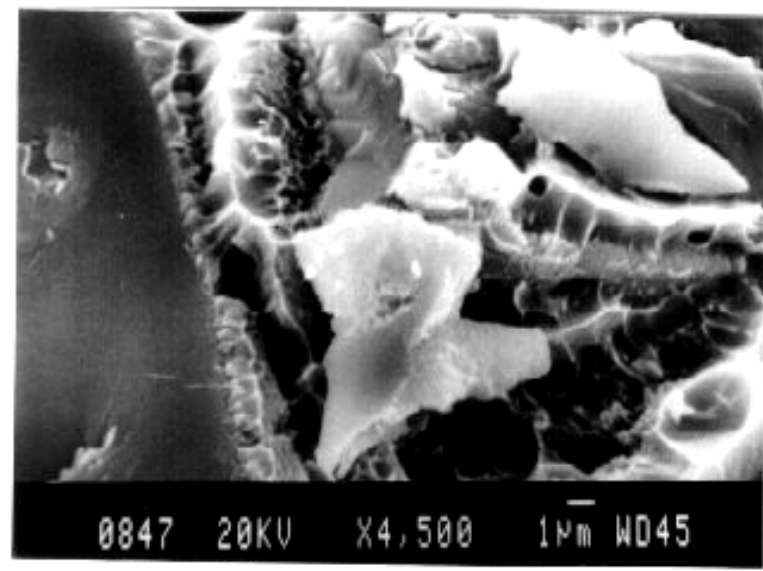

(c)

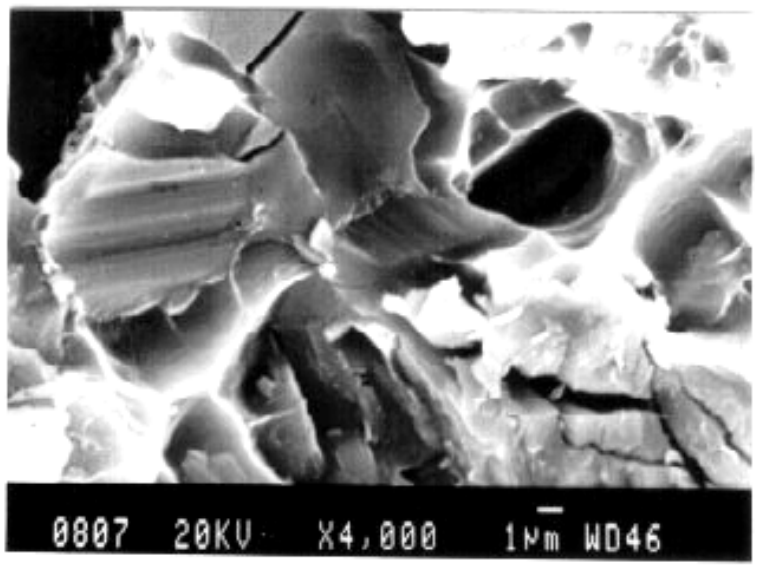

(b)

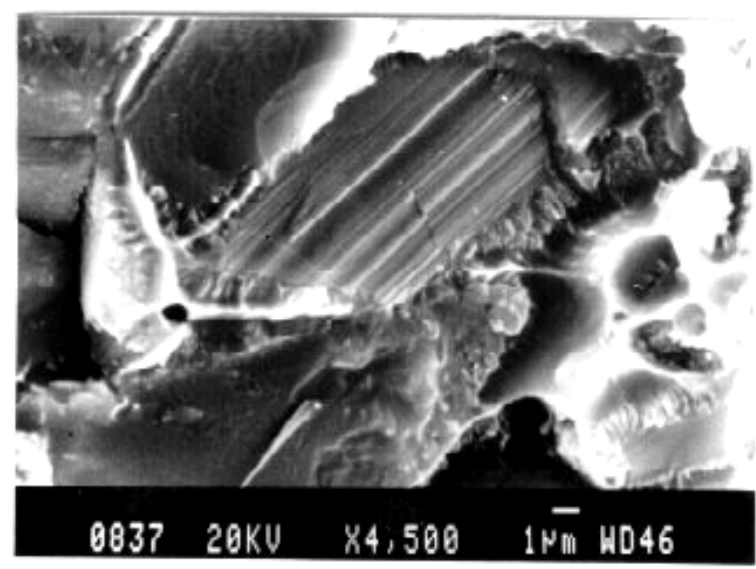

(d)

Fig .4 Fracture in composites processed at $900^{\circ} \mathrm{C}$ a) Low magniFication indicating particle fracture and matrix deformation; b) matrix deformation in as solutionised conditions; c) and d) matrix deformation in UA and $O A$ conditions respectively. Extensive deformation is observed very near the interface while the rest of the matrix deforms as a ridge. 


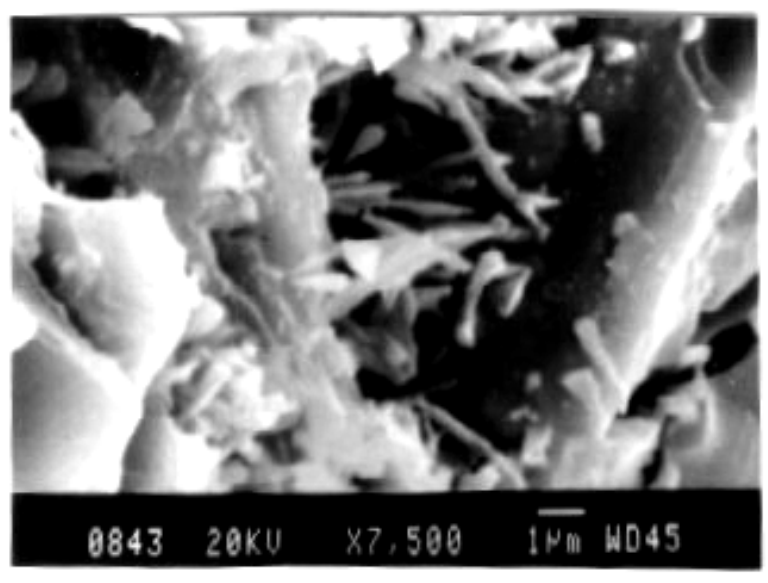

(a)

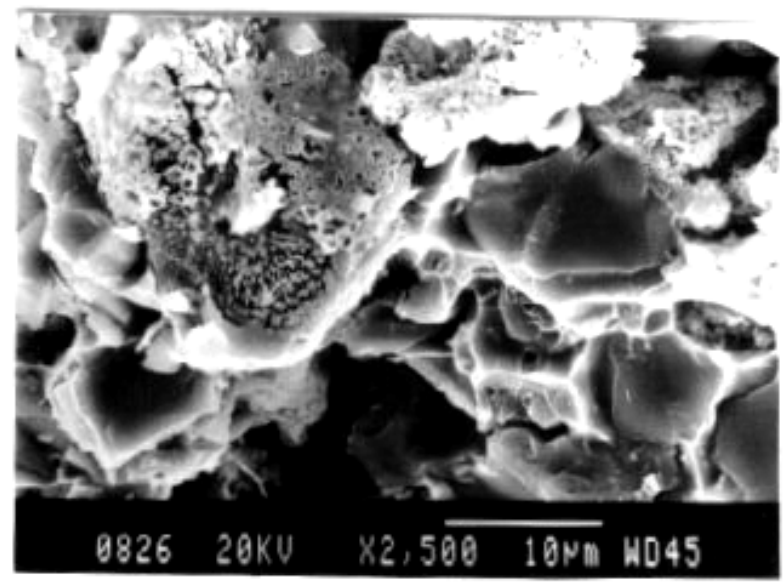

(b)

Fig. 5 Changes in $\mathrm{Mg}_{2} \mathrm{Si}$ morphology in the matrix. $\mathrm{Mg}_{2} \mathrm{Si}$ is present as Fine needles in underaged conditions (a) and as large precipitates in overaged conditions (b).

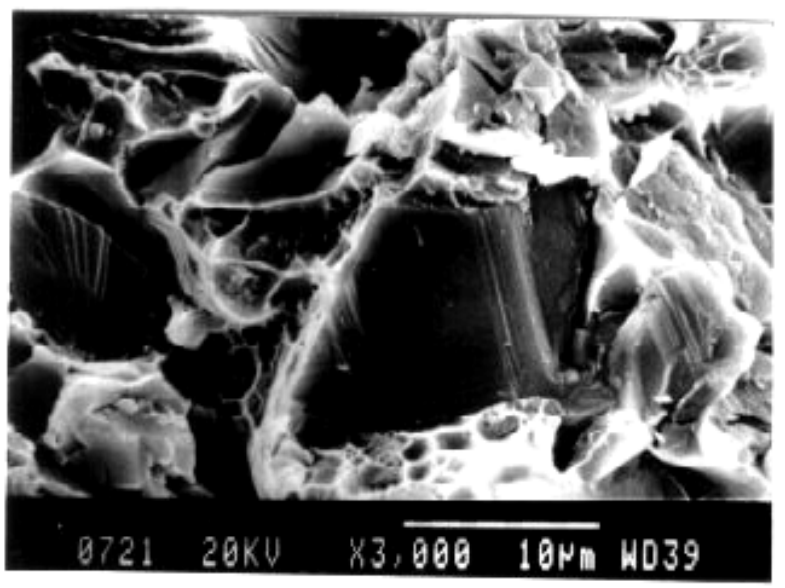

a)

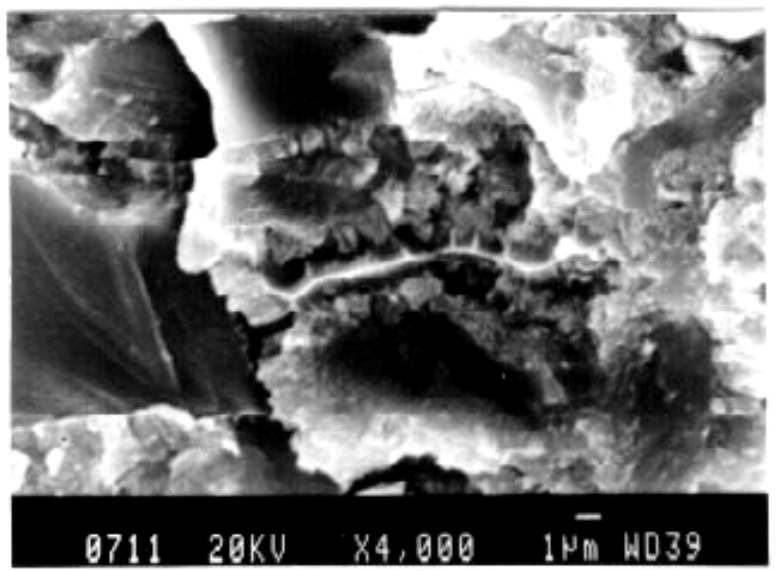

b)

Fig. 6 Fracture in composite processed at higher temperatures. The matrix shows: a) Fine dimples due to decohesion of AIN (process temp. - $950^{\circ} \mathrm{C}$ ) and b) deformation as shallow ridges between AIN particles (process temp. - $1000^{\circ} \mathrm{C}$ ) 


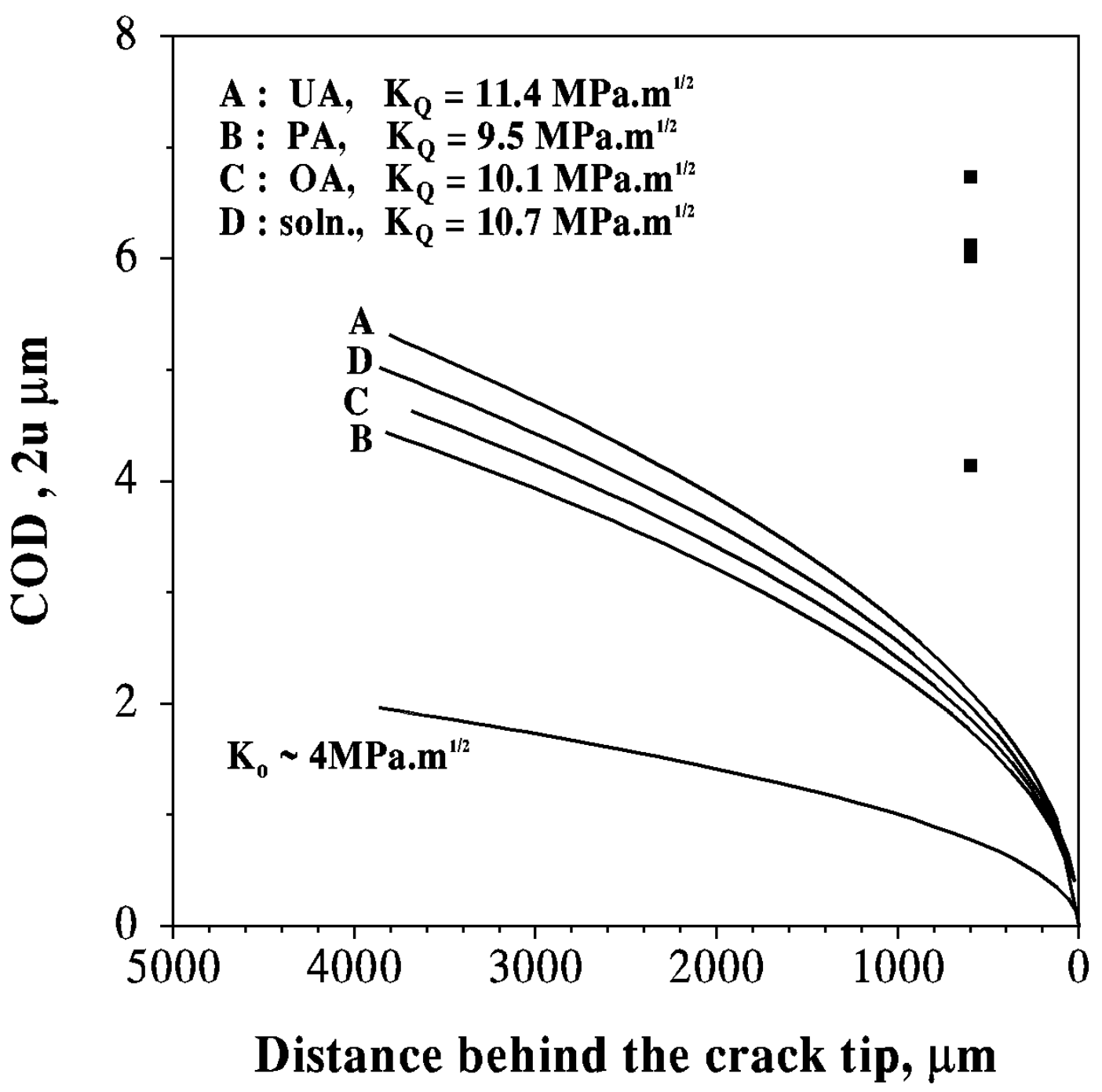

Fig 7 a 


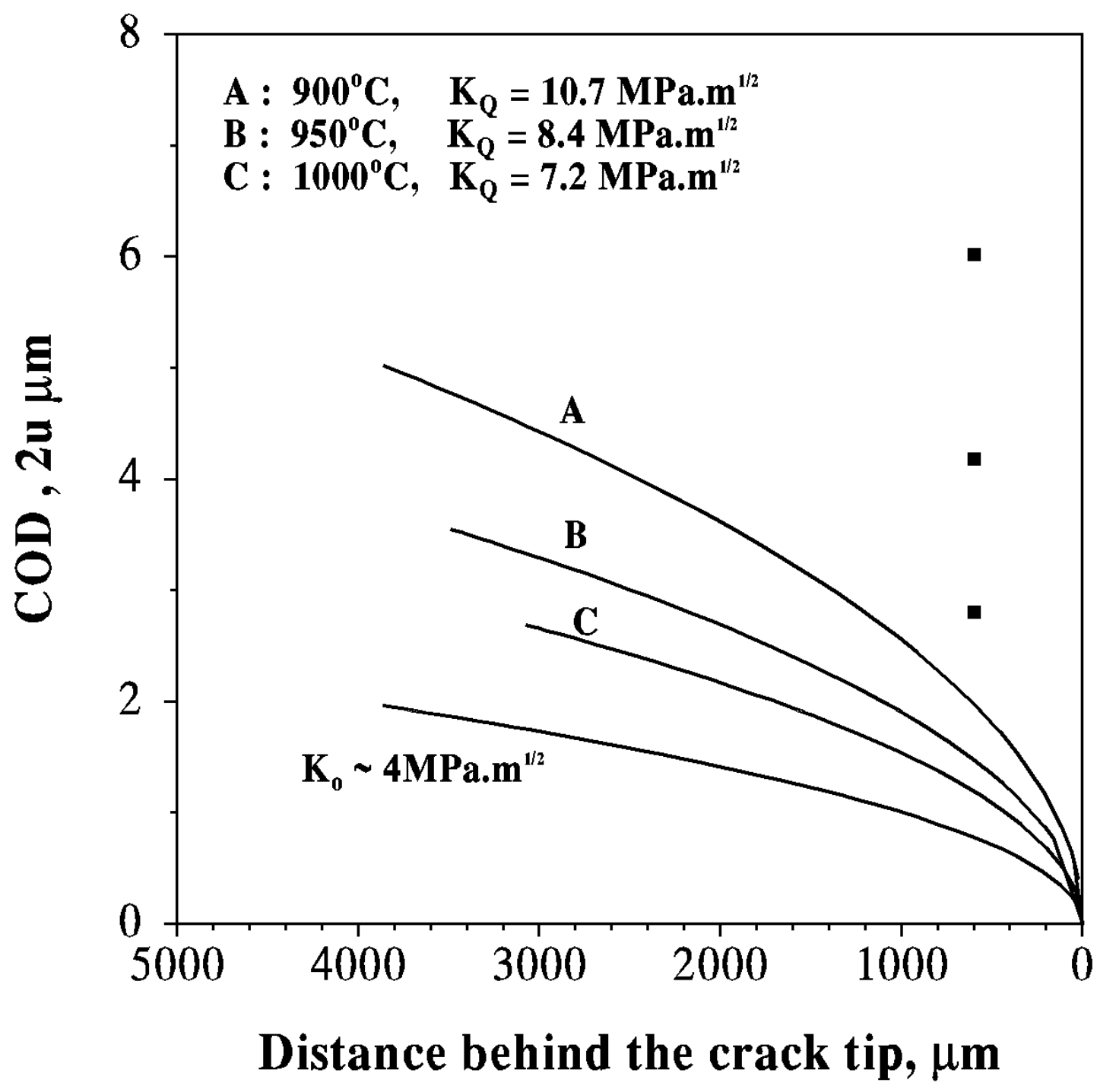

Fig. 7 b

Fig. 7 Theoretical computed crack profile in the composites from equation 6 as a function of a) ageing conditions and b) process temperature. The critical COD to failure $2 u^{*}$ is plotted at a distance of $600 \mu \mathrm{m}$ behind the crack tip. 


\section{TABLES}

Table 1 Relative plastic constraint and fracture toughness of the composites as a function of microstructural parameters

\begin{tabular}{|c|c|c|c|c|c|c|c|c|}
\hline Composite & $\begin{array}{c}\text { Volume } \\
\text { fraction } \\
V_{\mathrm{f}}\end{array}$ & $\begin{array}{c}\text { Interparticle } \\
\text { spacing } \lambda_{\mathrm{i}}, \\
\mu \mathrm{m}\end{array}$ & $\begin{array}{c}\text { Matrix } \\
\text { hardness, } \\
\text { VHN }\end{array}$ & $\begin{array}{c}\text { E, } \\
\text { GPa }\end{array}$ & $\begin{array}{c}\text { Measured } \\
\text { Displacement } \\
\mu \mathrm{m}\end{array}$ & $\begin{array}{c}\text { Plastic } \\
\text { Zone, } \\
\mu \mathbf{m}\end{array}$ & $\begin{array}{c}\text { Plastic } \\
\text { Constraint } \\
\text { P }\end{array}$ & $\begin{array}{c}\mathbf{K}_{\mathbf{Q}} \\
\mathbf{M P a} \sqrt{ }{ }_{\mathbf{m}}\end{array}$ \\
\hline $\begin{array}{l}\text { Base alloy } \\
900^{\circ} \mathrm{C}, \mathrm{As}\end{array}$ & 0.61 & 8.9 & $\begin{array}{c}63 \\
132\end{array}$ & $\begin{array}{c}69 \\
195\end{array}$ & 1.73 & 13.72 & & $\begin{array}{c}18 \\
10.7\end{array}$ \\
\hline $\begin{array}{l}\text { solutionised } \\
145^{\circ} \mathrm{C}, 1 \\
\text { hour U }\end{array}$ & 0.61 & 8.9 & 116 & 195 & $\begin{array}{l}1.24 \\
1.27\end{array}$ & $\begin{array}{c}9.83 \\
10.08\end{array}$ & $\begin{array}{c}1.4 \\
1.36\end{array}$ & 11.4 \\
\hline $\begin{array}{l}195^{\circ} \mathrm{C}, 3 \\
\text { hours PA }\end{array}$ & 0.62 & 8.9 & 165 & 195 & 1.18 & 9.38 & 1.47 & 9.5 \\
\hline $\begin{array}{l}220^{\circ} \mathrm{C}, 12 \\
\text { hours, OA }\end{array}$ & 0.61 & 8.9 & 131 & 195 & 1.27 & 10.1 & 1.36 & 10.1 \\
\hline $950^{\circ} \mathrm{C}$ & 0.61 & 8.6 & 206 & 206 & 0.97 & 7.72 & 1.78 & 8.4 \\
\hline $1000^{\circ} \mathrm{C}$ & 0.62 & 8.7 & 330 & 219 & 0.8 & 6.63 & 2.17 & 7.2 \\
\hline
\end{tabular}

Table 2 Comparison of calculated and experimentally measured steady state toughness

\begin{tabular}{|c|c|c|c|c|c|c|}
\hline Composite & $\begin{array}{c}\sigma_{\mathrm{y}}=\mathbf{P} \sigma_{0} \\
\mathbf{M P a}\end{array}$ & $\begin{array}{l}\mathbf{u}^{*} \\
\mu \mathbf{m}\end{array}$ & $\begin{array}{c}\text { Measured } \\
K_{s s}, \text { MPa } \sqrt{m}\end{array}$ & $\begin{array}{c}\text { Calculated } K_{s s}, \\
\text { MPa } \sqrt{m}\end{array}$ & $\begin{array}{c}\text { Bridging } \\
\text { Zone, } \mathbf{L}, \mathbf{m m} .\end{array}$ & $L / c$ \\
\hline $\begin{array}{l}900^{\circ} \mathrm{C}, \text { As } \\
\text { solutionised }\end{array}$ & 387 & 3.01 & 16 & 14.5 & 1.33 & 0.36 \\
\hline $145^{\circ} \mathrm{C}, 1$ hour, UA & 375 & 3.06 & 14.5 & 14.3 & 1.37 & 0.49 \\
\hline $1^{\circ} 5^{\circ} \mathrm{C}, 3$ hours, $\mathrm{PA}$ & 406 & 2.07 & 13 & 12.5 & 0.63 & 0.20 \\
\hline $220^{\circ} \mathrm{C}, 12$ hours, $\mathrm{OA}$ & 375 & 3.37 & 14 & 15.1 & 1.67 & 0.41 \\
\hline $950^{\circ} \mathrm{C}$ & 491 & 2.09 & 9.3 & $11.5(12.9)$ & 0.64 & 0.21 \\
\hline $1000^{\circ} \mathrm{C}$ & 598 & 1.40 & 6.8 & $10.4(12.2)$ & 0.29 & 0.10 \\
\hline
\end{tabular}




\section{LIST OF FIGURES}

Fig. 1 Microstructure of the composites a) processed at $900^{\circ} \mathrm{C}$; b) precipitate morphology in $\mathrm{OA}$ condition; c) processed at $950^{\circ} \mathrm{C}$ and d) processed at $1000^{\circ} \mathrm{C}$

Fig. 2 Matrix hardness as a function of ageing temperature and time

Fig. 3 Load vs. COD and the corresponding R-curves of the composites under differing ageing condition

Fig .4 Fracture in composites processed at $900^{\circ} \mathrm{C}$ a) Low magniFication indicating particle fracture and matrix deformation; b) matrix deformation in as solutionised conditions; c) and d) matrix deformation in UA and OA conditions respectively. Extensive deformation is observed very near the interface while the rest of the matrix deforms as a ridge.

Fig. 5 Changes in $\mathrm{Mg}_{2} \mathrm{Si}$ morphology in the matrix. $\mathrm{Mg}_{2} \mathrm{Si}$ is present as Fine needles in underaged conditions (a) and as large precipitates in overaged conditions (b).

Fig. 6 Fracture in composite processed at higher temperatures. The matrix shows: a) Fine dimples due to decohesion of AlN (process temp. - $950^{\circ} \mathrm{C}$ ) and b) deformation as shallow ridges between AIN particles (process temp. - $1000^{\circ} \mathrm{C}$ )

Fig. 7 Theoretical computed crack proFile in the composites from equation 6 as a function of a) ageing conditions and $b$ ) process temperature. The critical COD to failure $2 \mathrm{u}^{*}$ is plotted at a distance of $600 \mu \mathrm{m}$ behind the crack tip

\section{LIST OF TABLES}

Table $1 \quad$ Microstructural parameters and fracture toughness of the composites

Table 2 Relative plastic constraints on the deforming matrix and the predicted toughness from equation 5 . 